
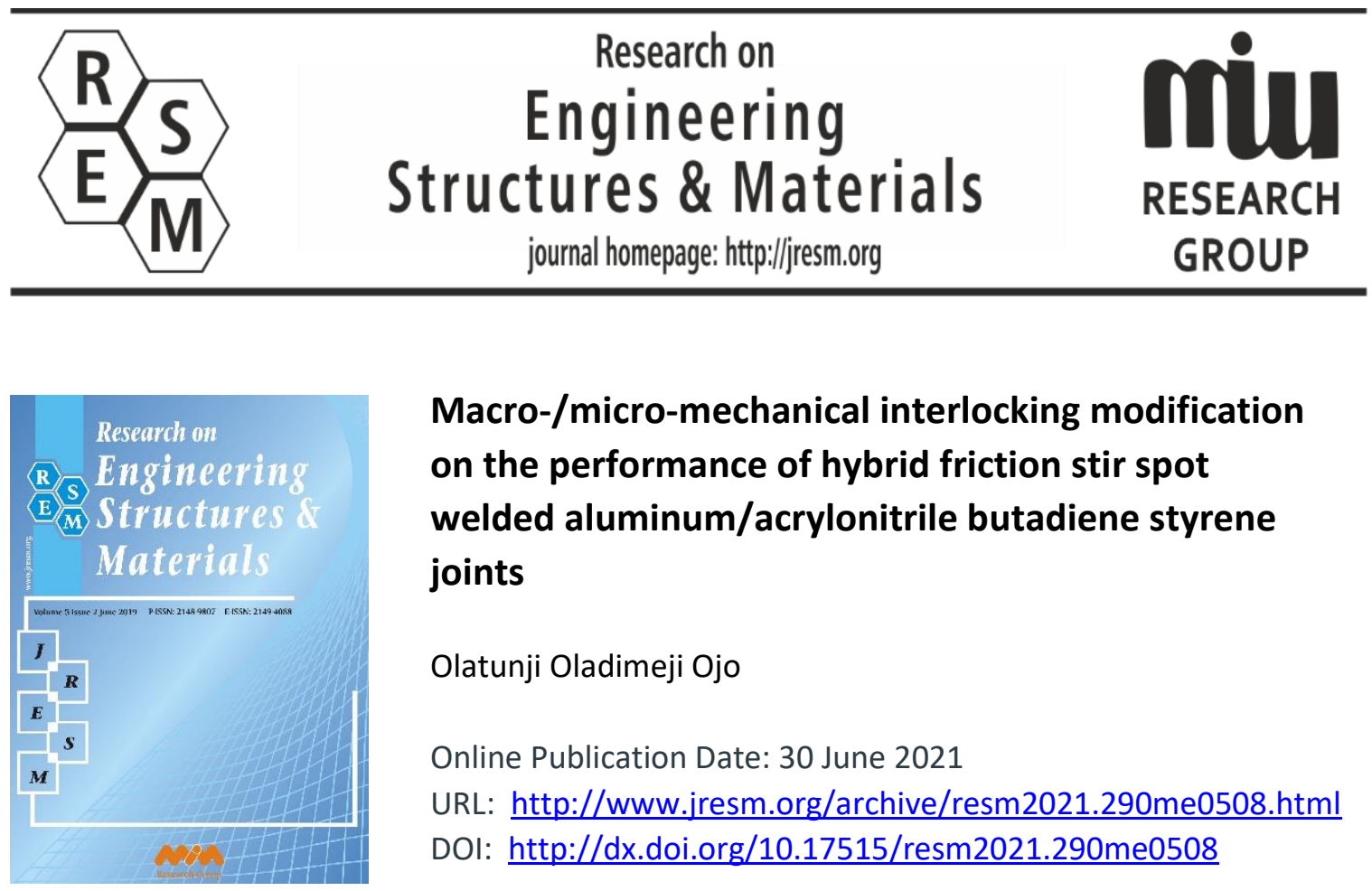

\title{
Macro-/micro-mechanical interlocking modification on the performance of hybrid friction stir spot welded aluminum/acrylonitrile butadiene styrene joints
}

Olatunji Oladimeji Ojo

Online Publication Date: 30 June 2021

URL: http://www.jresm.org/archive/resm2021.290me0508.html

DOI: http://dx.doi.org/10.17515/resm2021.290me0508

Journal Abbreviation: Res. Eng. Struct. Mater.

\section{To cite this article}

Ojo OO. Macro-/micro-mechanical interlocking modification on the performance of hybrid friction stir spot welded aluminum/acrylonitrile butadiene styrene joints. Res. Eng. Struct. Mater., 2021; 7(4): 617-633.

\section{Disclaimer}

All the opinions and statements expressed in the papers are on the responsibility of author(s) and are not to be regarded as those of the journal of Research on Engineering Structures and Materials (RESM) organization or related parties. The publishers make no warranty, explicit or implied, or make any representation with respect to the contents of any article will be complete or accurate or up to date. The accuracy of any instructions, equations, or other information should be independently verified. The publisher and related parties shall not be liable for any loss, actions, claims, proceedings, demand or costs or damages whatsoever or howsoever caused arising directly or indirectly in connection with use of the information given in the journal or related means.

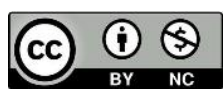
Published articles are freely available to users under the terms of Creative Commons Attribution - NonCommercial 4.0 International Public License, as currently displayed at here (the "CC BY - NC"). 


\title{
Research on Engineering Structures \& Materials
}

journal homepage: http://jresm.org

\section{Macro-/micro-mechanical interlocking modification on the performance of hybrid friction stir spot welded aluminum/acrylonitrile butadiene styrene joints}

\author{
Olatunji Oladimeji Ojo
}

Department of Industrial and Production Engineering, Federal University of Technology Akure, PMB 704, Akure, Nigeria

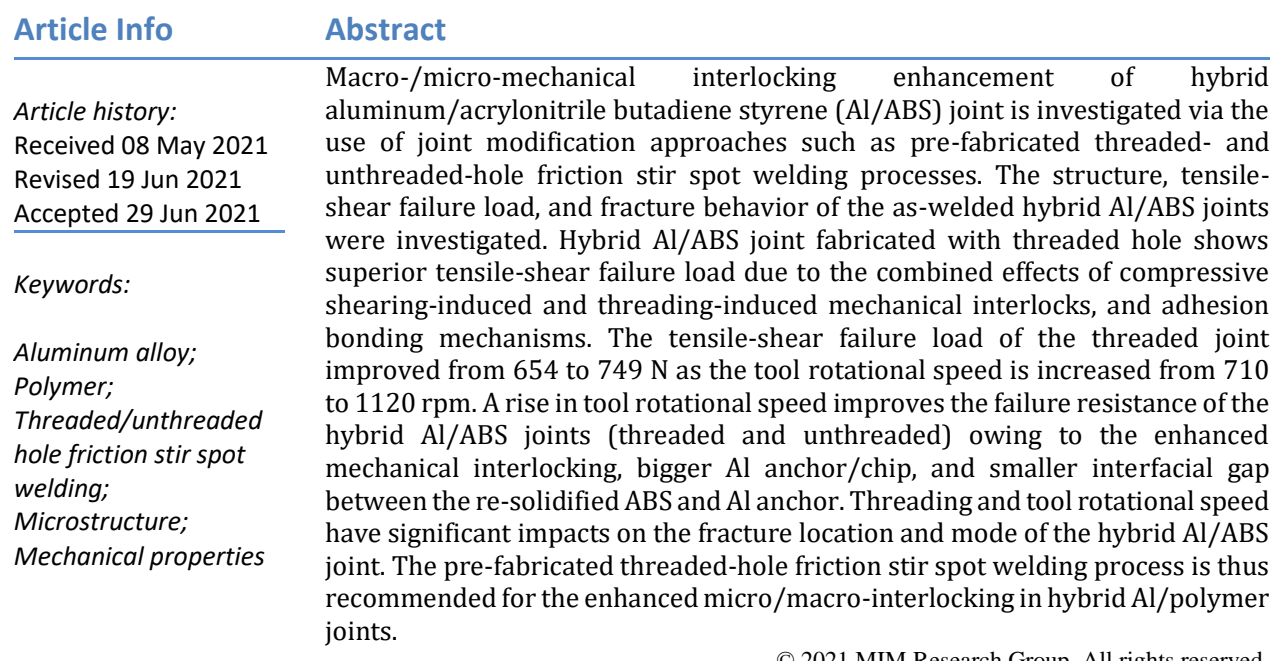

(C) 2021 MIM Research Group. All rights reserved.

\section{Introduction}

Modern industries (such as aerospace and aviation, automotive, and high-speed trains manufacturing industries) continuously seek product design flexibility, cost-saving, high performance, fuel efficiency, high elastic modulus, and specific strength, reduced carbon footprint, and high reliability through the new paradigm shift of using light-weight materials in fabricating engineering structures $[1,2]$. Polymers and hybrid metalpolymeric materials offer the potential of achieving the aforementioned goals, especially in drone manufacturing. However, the joining of polymers and metals is difficult through the traditional fusion processes due to the large physiochemical differences between the materials. The available metal/polymer joining processes in literature have been summarized as adhesive bonding, riveting, bolt connections, pin inserts (z-pin), welding (laser, induction, ultrasonic, braze, and resistance welding), and plastic deformation-aided joining processes such as friction stir (spot) welding, hot/self-pierce riveting, and mechanical clinching [3-5]. Susceptibility to environmental conditions (temperature and humidity) and a high disparity between the surface free energies of metal and polymers make adhesive bonding undesirable for metal/polymer joints [6]. Weight addition and induced stress-concentration are also major challenges of mechanically joined metal/polymer materials. Hybrid welding processes such as laser-TIG and diode laserassisted joining of $\mathrm{Al} /$ polymer have recently been investigated by Wang et al. [7], and

Corresponding author: ojooladimeji90@yahoo.com 
Lambiase \& Genna [8] respectively. The depth of laser penetration and the induced inherent bubbles were reported to affect the fracture modes and strength of the metalpolymer joints. However, solid-state friction stir (spot) joining of $\mathrm{Al} /$ polymers has evolved to be a cost-effective approach (with a process-joint modification capability) for improving the performance and load-bearing capacity of $\mathrm{Al} /$ polymer joints. Thus, this paper explores the joint modification-interlocking approach in enhancing the performance of the hybrid $\mathrm{Al} / \mathrm{ABS}$ joint.

Literature shows that a lot of works on friction stir welding (FSW) of Al/polymer have been studied. For instance, Patel et al. [1] investigated the friction stir welded hybrid AA6061T6/polycarbonate joints. The occurrence of improved heat concentration and mechanically interlocked $\mathrm{Al} /$ polymer (chip interlocking) at the stir zone was reported to improve the tensile strength of the joint to about $14.9 \mathrm{MPa}$ at tool rotational speed and travel speed of $500 \mathrm{rpm}$ and $40 \mathrm{~mm} / \mathrm{min}$ respectively. Mechanical interlocking also improved the tensile strength of the AA6061/ABS (acrylic) joints to about $7 \mathrm{MPa}$ (at 1000 $\mathrm{rpm}$ and $40 \mathrm{~mm} / \mathrm{min}$ ) while plastic deformation-aided hardness rise ensued as the welding speed was increased in the studies of Dalwadi et al. [9]. Macro-level and atomically locked interfaces (with no chemical bond) are established in the friction stir welded $\mathrm{Al} /$ polypropylene joint [10]. Liu et al. [11] investigated the interfacial zone of the friction lap welded $\mathrm{Al} /$ polyamide 66 joints. It was reported that the formation of $\mathrm{Al}-\mathrm{O}-\mathrm{C}$ bonds at the weld interface improved the resultant joint strength. The shear strength of the Al/PA66 joints was significantly improved by a combination of C-O-Al bonds and mechanical interlocking [12]. The interfacial bonding strength was reported not to be dependent on the induced welding temperature, provided an atomic contact between the Al alloy and PA66 was established. The formation of the interaction layer and internal voids in the AA5754/polymethylmethacrylate (T-joint) was stated to impair the strength and hardness of the joint [13]. However, the defects were cutback by either decreasing the tool travel speed or increasing the tool rotational speed. Derazkola \& Elyasi [14] investigated the impact of process parameters on the friction stir welded AA5058/polycarbonate joints. It was revealed that the joint strength and fracture were controlled by the level of the tool rotational speed while the travel speed controlled the Al fragments within the polycarbonate matrix. Excessive heat accumulation induces local thermal degradation (LTD) while the combined effect of LTD and molten state of the polymer affects the lap shear strength of the glass-fabric reinforced polyetherimide/Ti alloy joint [15].

A few modifications of the joining process have also been reported in the literature. Tool modification was studied by Huang et al. [6] while the friction stir lap welding of the AA6061-T6/polyether ether ketone was investigated. It was reported that an increase in the welding speed reduced the adhesion area and the $\mathrm{Al}$ anchor with the joint, thereby, producing a deteriorated mechanical interlocking. Ozlati et al. [16] utilized fused deposition modeling (FDM) with polypropylene filament to produce lap joints of Al$\mathrm{Mg} /$ polypropylene. It was stated that the substrate preheating improved the bonding between the polymer sheet/additive part. Hajideh et al. [17] have shown that the introduction of $\mathrm{Cu}$ powder to the dissimilar polypropylene/acrylonitrile butadiene styrene joint increased the hardness and tensile strength of the joint by 30 and $36 \%$ respectively. Hong et al. [18] investigated the combination of nanoparticle deposition and friction stir spot welding systems in fabricating carbon/Al metal matrix composite joint. This nanoparticle-aided joining approach was reported to improve the toughness and strength of the resultant joint. Derazkola \& Simchi [19] employed an in-situ colloidal (nanoparticle) injection technique also known as fed friction stir processing in producing AA6062/ABS joints. Thermal stability was aided through the presence of nanoparticles in the joints while the mechanical properties of the resultant joints were significantly improved when compared with the conventional friction stir processed joints. Bending strength of $56 \mathrm{MPa}$ 
(20\% improvement), a tensile strength of $60 \mathrm{MPa}$ (14\% improvement), and hardness of 79 ShoreD (11\% improvement) were obtained with the new fed friction stir processed AA6062/ABS joint. Meng et al. [20] investigated the friction self-riveting of AA2060T8/polymer matrix composite joints. The combined effect of adhesion and multi-scale mechanical interlocks was reported to produce a maximum tensile strength of about 27 MPa. Liu et al. [21] investigated the hole-clinching of the AA5754/carbon-fiber-reinforced polymer joints. It was revealed that joint delamination was severe in the $\mathrm{Al} /$ polymer joints fabricated with complex angle plies. Lambiase \& Paoletti [22] investigated the frictionassisted clinching of $\mathrm{Al} /$ carbon fiber-reinforced polymer. This new approach of joining was reported to increase material formability and joint strength.

Surface modification of Al alloy for enhanced interlocking is another approach to improving Al/polymer strength. Improved strength of AA5052/polypropylene joint (up to a factor of 6) was established with an anodizing pre-treatment process (in a sulphuric acid electrolyte) in the works of Aliasghari et al. [23]. Aliasghari et al. [24] employed the plasma electrolytic oxidation (PEO) technique to modify the surface of AA5052 Al alloy before being joined to a polypropylene via the use of friction stir spot welding process. The PEO generated a highly porous and rough surface that favors mechanical interlocking with the polymer. The pretreatment (PEO) technique was reported to have improved the tensile strength of the resultant joint by a factor of 3 (three) when compared to the as-welded FSSW joints. Han et al. [25] studied the friction spot joining of $\mathrm{Al} /$ polypropylene via the use of the surface laser pretreatment process. The laser pretreating of the Al surface caused the formation of a deep porous structure on the $\mathrm{Al}$ and this occurrence aided mechanical interlocking and changed the reaction features (chemical bonding) between the $\mathrm{Al} /$ polypropylene joint. Goushegir et al. [26] reported that sandblasting was suitable to induce surface roughness on AA2024-T3 alloy and this improved the performance of the friction stir spot welded AA2024-T3/poly(phenylene sulfide) joint. Nagatsuka et al. [27] studied the friction stir welding of AA5052 Al alloy and carbon fiber-reinforced polyamide 6 sheets. It was reported the surface grinding of the Al alloy aided the generation of $\mathrm{Al}(\mathrm{OH}) 3$ on the alloy which improved the joint strength. The occurrence of the $\mathrm{Al} /$ polymer (interfacial) Mg oxide layer aids the joining process.

The latest modification approach of improving $\mathrm{Al} /$ polymer joints is the friction stir spot welding (FSSW) approach based on a pre-drilled hole methodology. In this case, a hole is drilled in the Al plate and the molten polymer flows into the pre-drilled hole (during the FSSW process) to establish an interlocking between the Al and the polymer after solidification. This new approach has recently been studied by Paidar et al. [28], Pabandi et al. [29], and Aliasghari et al. [30]. It was reported that the infiltration of polymer into holes provided mechanical keying responsible for improved joint strength in the works of Aliasghari et al. [30]. This paper thus focuses on the use of a pre-drilled hole methodology in producing hybrid $\mathrm{Al} / \mathrm{ABS}$ joints by examining threaded and unthreaded holes for macro/micro-mechanical interlocking enhancement. It is necessary to clarify whether a hole or a combination of hole and threading is paramount for enhancing the load-bearing capacity of the Al/ABS joint to save manufacturing costs and time. The microstructure, tensile-shear failure load, and fracture behavior of the as-welded hybrid Al/ABS joints (with threaded and unthreaded holes) are thus clarified in this paper.

\section{Materials and Method}

The base materials employed for this research are $4 \mathrm{~mm}$ thick acrylonitrile butadiene styrene (ABS) and AA1050 Al alloy sheets respectively. The as-received polymeric and $\mathrm{Al}$ sheets were cleaned with acetone and then cut to the dimensions of $100 \mathrm{~mm} \times 30 \mathrm{~mm}$ respectively. Overlapped friction stir spot welding (having an overlapped area of $30 \mathrm{~mm} \times$ $30 \mathrm{~mm}$ ) with the Al base material as the upper sheet and the ABS as the lower sheet was 
designed for this research. Before the joining process, pre-weld preparations (drilling and threading) were carried on the $\mathrm{Al}$ alloy sheets to facilitate the formation of micro-/macromechanical interlocking of the $\mathrm{Al}$ and polymer sheet during the welding process. The center/middle of the overlapped area of the $\mathrm{Al}$ sheet was drilled with a $5 \mathrm{~mm}$ drill bit (to produce a through-hole) for some set of $\mathrm{Al}$ sheets while the other set of $\mathrm{Al}$ sheets were further threaded with an M6.5 mm tap. These pre-processed Al alloys were then placed on the ABS sheets and rigidly clamped to the worktable of the welding machine (MV-2 Maximill Milling Machine) before the joining process. For convenience, the joint obtained with a drilled hole is termed " $\mathrm{DH}$ " joint while that of a combination of drilling and threading is termed "DHT" joint in this paper. The schematics of the joining process are shown in Fig.1. The axis of the welding tool coaxially aligns with that of the drilled hole before the commencement of the joining process. This attribute is paramount for the success of the DH and DHT joints. A probeless tool having a $12 \mathrm{~mm}$ diameter was fabricated from the heat-treated high-speed steel (HSS) and used for the welding process. The rotating welding tool establishes contact with the top of the $\mathrm{Al}$ alloy and penetrates the alloy without reaching the ABS side. The generated in-process temperature rises above the melting point of the ABS and the molten ABS fills the pre-drilled Al hole (threaded and unthreaded) during the welding process. The welding parameters used for this research are tool rotational speed (710-1120 rpm), plunge depth (0.8 - $1.2 \mathrm{~mm})$, and constant dwell time (5 s) respectively.

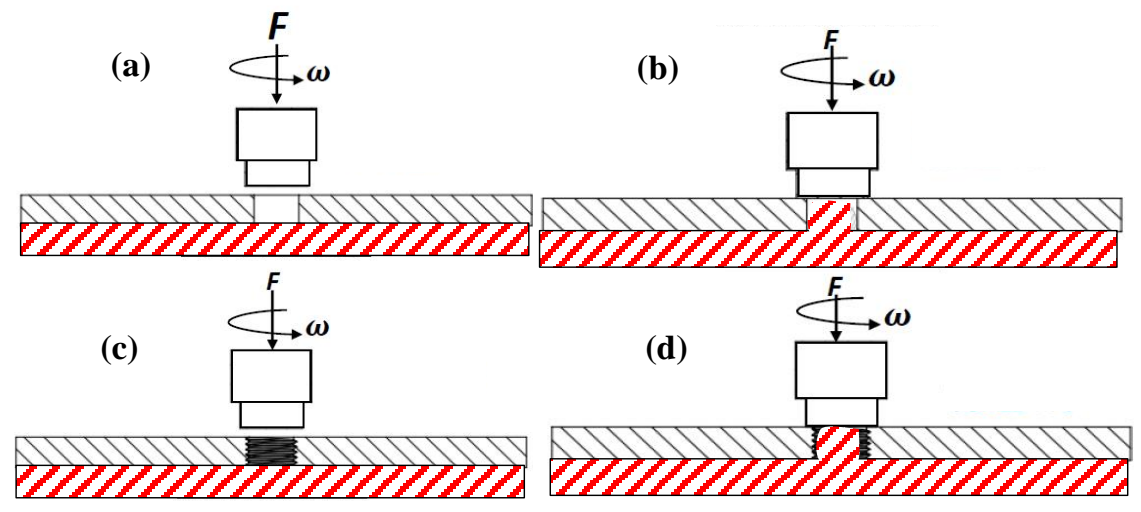

Fig. 1 Schematic of the joining process (a) and (b) DH joining before and after tool plunging, (c) and (d) DT joining process before and after tool plunging

The in-process and local environmental conditions (temperature, and humidity) of the $\mathrm{Al} / \mathrm{ABS}$ joints were obtained via the use of three K-type thermocouples embedded into the interfacial region of the $\mathrm{Al} / \mathrm{ABS}$ joints at distances of 10,15 , and $30 \mathrm{~mm}$ from the nugget center. The other ends of the thermocouples were connected to a data logger and a computer system for real-time monitoring and in-situ recording of the in-process joining conditions. The cross-section of the DHT and DH joints were prepared according to the ASTM E3-11 standard. The samples were ground with silicon carbide papers (of 200, 400, 600,800 , and 1000 grit numbers), and polished with the aid of diamond pastes having particle sizes of 5 and $1 \mu \mathrm{m}$. The Al side of the prepared samples was then etched in Keller's reagent while ethanol was used for the polymeric side of the joint. The samples were then examined under an optical microscope. The tensile strengths of the joints were investigated according to the ASTM E8M-16a standard at a constant strain rate of $0.04 \mathrm{~min}^{-}$ ${ }^{1}$ by employing an INSTRON universal tensile testing machine. The average of three tensile 
results was recorded as the actual result in this paper. The fracture surfaces of the joints after tensile loading were examined in a JOEL-JSM 7600F scanning electron microscope to understand the fracture mechanism of the joints.

\section{Results and Discussion}

\subsection{Temperature History and Weld Appearance}

Fig. 2 shows the real time-temperature/humidity graph of the hybrid Al/ABS joint obtained at different tool rotational speeds. AT, RH, TA, TB, and TD represent the atmospheric temperature, relative humidity, and temperature readings of the $1 \mathrm{st}, 2 \mathrm{nd}$, and $3 \mathrm{rd}$ thermocouples respectively. The atmospheric temperature (AT) at which the joining process was carried out was about $30 \mathrm{oC}$ (see the red line in Fig.2) while the relative humidity $(\mathrm{RH})$ of approximately $78 \%$ was recorded before the commencement of the welding process. The local RH progressively declines while fluctuating during the welding process due to the complex frictionally-induced heat input and heat dissipation into and around the local weld environment (see the blue trendline in Fig.2). The sources of heat input (generation) in a hybrid $\mathrm{Al} /$ polymer joint have been stated to include tool-Al alloy contact friction, Al alloy-polymer friction, and plastic deformation of $\mathrm{Al}$ and polymer [24]. A sharp temperature rise was recorded as the welding process commenced at different tool rotational speeds. The proximity of the thermocouple to the weld nugget zone is observed to be linearly proportional to the attained peak temperature.

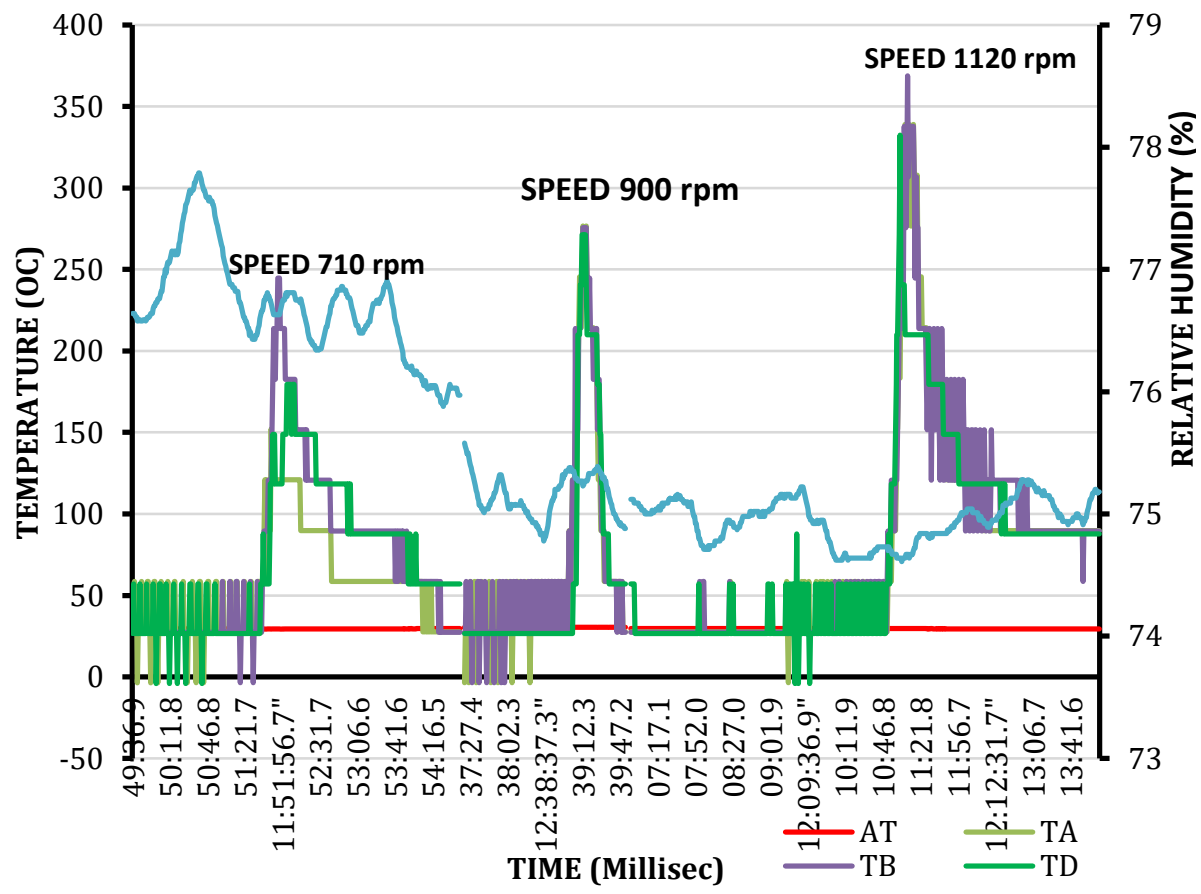

Fig. 2 Real-time - temperature/humidity series graph as a function of variable tool rotational speeds ("AT": Atmospheric Temperature; "TA": 1st Thermocouple; "TB":

2nd Thermocouple; "TD": 3rd Thermocouple; and "RH": Relative humidity).

The maximum frictionally and plastic deformation-induced peak temperatures of about $245,276,369 \mathrm{oC}$ were obtained at tool rotational speeds of 710,900 , and $1120 \mathrm{rpm}$ respectively in Fig.2. This incidence is observed due to the direct interrelationship between 
tool rotational speed and heat input [31-33]. The attained peak temperatures at respective tool rotational speeds are lesser than the melting temperature of the pure $\mathrm{Al}$ alloy (about $630 \mathrm{oC}$ ) but are greater than the melting temperature of the ABS polymer (about $160 \mathrm{oC}$ ). This occurrence indicates that frictionally-aided plastic shear deformation (material flow) is the predominant occurrence at the $\mathrm{Al}$ side of the hybrid $\mathrm{Al} / \mathrm{ABS}$ joint while heat transferaided melting of the beneath ABS polymer is an expected outcome. The Al side is a good heat and electrical conductor having a thermal conductivity of approximately $167 \mathrm{~W} / \mathrm{m} / \mathrm{K}$. This attribute is adjudged to promote the transfer of thermal energy or heat input to the polymer side at the tool under-shoulder region beneath the Al side (or at the faying region between the $\mathrm{Al}$ and $\mathrm{ABS}$ ). The $\mathrm{ABS}$ is a poor conductor of heat having a thermal conductivity of about $0.19 \mathrm{~W} / \mathrm{m} / \mathrm{K}$. This implies that the ABS polymer will act as a local heat sink and this occurrence will aid the local melting of the ABS polymer at the faying region between the base materials. Aliasghari et al. [24] reported that the induced heat input is distributed (via conduction) and melting of the polymer (via absorption or heat sink). The post-weld visual observation of the hybrid Al/ABS joints is thus examined in Fig.3 to understand the role/impact of the inherent frictionally-induced heat input on the ABS side and the hybrid joints.

There is no significant difference between the surface appearance of the DT and DHT hybrid $\mathrm{Al} / \mathrm{ABS}$ joints obtained at the same level of parameter combination. As a result, the surface outlook associated with the hybrid Al/ABS joints at different tool rotational speeds is provided in Fig.3 irrespective of the type of joint.

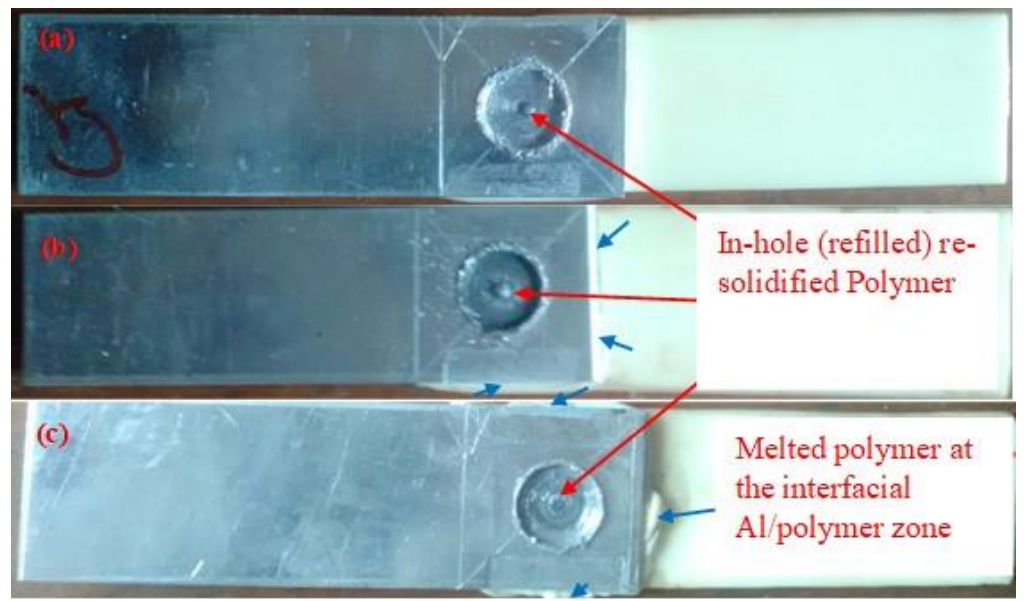

Fig. 3 As-welded Al/ABS joints at (a) 710 rpm, (b) 900 rpm, (c) $1120 \mathrm{rpm}$

Fig.3a-c shows the in-hole/refilled and re-solidified ABS polymer interlocked with the Al alloy. The local frictionally-induced heat transfer to the ABS polymer beneath the tool shoulder is sufficient to cause the local melting of the ABS polymer (in agreement with Fig.2) as infiltrated or filled (threaded and unthreaded) holes are revealed in Fig.3a-c. The downward axial force of the tool (tool downward plunging) is adjudged to have induced some level of pressure on the local molten pool of the ABS polymer (at the faying region) to force an upward drive of the molten ABS polymer into the pre-drilled holes (empty cavities). The molten ABS matrix thus fills the pre-drilled hole with and without threading in the Al sheets (in Fig.3) to establish mechanical interlocking of the Al alloy and the ABS polymer at the tool rotational speeds of 710,900 , and 1120 rpm respectively. This implies that tool rotational speeds between 710 and $1120 \mathrm{rpm}$ are suitable for establishing efficient in-hole re-solidified polymer in the hybrid Al/ABS joint. However, Fig.3b and c reveal the presence of palpable melted polymer (at the interfacial Al/ABS zone) being 
extruded out of the interfacial zone (see the blue arrows in Fig.3). This occurrence is due to the increase in heat input (or peak temperature in Fig.2) as the tool rotational speed is increased. The fluidity of the ABS polymer is enhanced by higher tool rotational speeds and this phenomenon is a major factor for the outstretched flowing of the melted ABS polymer out of the interfacial/faying region. The heat transfer to the ABS sheet beneath the Al alloy at the overlapped and interfacial region (between the Al and the ABS or outside of the tool under-shoulder region) establishes some degree of melting/softening which can favor adhesion between the two materials.

\subsection{Microstructure}

Fig. 4 shows the cross-section of the DH and DHT joints with a focus on the hole walls. The interlocking of the re-solidified ABS with the undulating/threaded wall or meshing of the re-solidified ABS polymer matrix with the pitch-crest of the hole wall is revealed in Fig.4a while that of the unthreaded (vertical) hole is revealed in Fig.4b. Evidence of randomly dispersed fine particles of the Al alloy (see the indicated yellow points in Fig.4a and c) entrapped within the re-solidified ABS matrix is observed. The occurrence of these Al particles in the ABS matrix is attributed to the severe plastic deformation and compressiveshearing effect of the $\mathrm{Al}$ side. This phenomenon leads to a somewhat fragmentation of the plasticized Al alloy as ABS matrix-embedded fine particles as indicated in Fig.4. A large Al anchor/chips are embedded in the re-solidified ABS matrix as observed in the DH joint (see Fig.4b) due to the downward compressive-shearing of the Al alloy. The hole regions around the tool-shoulder plunged zone are examined in Fig.5 to understand the compressive-shearing effect of the plunging tool on the hole wall.
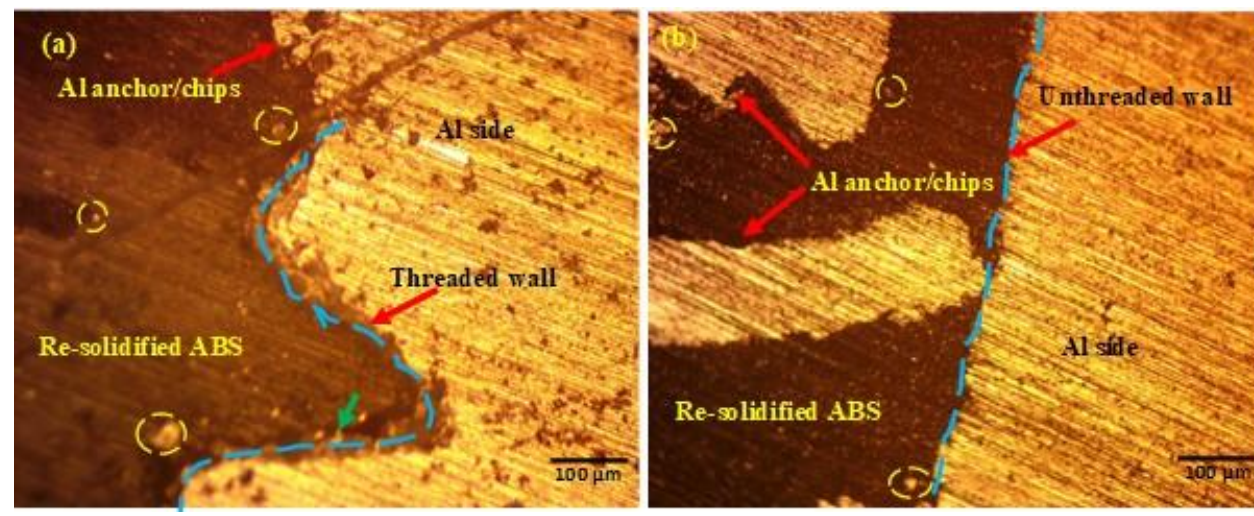

Fig. 4 Pre-fabricated hole wall after welding (a) threaded hole (DHT), (b) unthreaded hole (DH) at $710 \mathrm{rpm}$

The results of the preliminary experiment reveal that excessive plunging of the welding tool into the Al side reduces the effective (interlocked) hole height, and damages the prefabricated threading within the hole. Thus, a shallow plunge depth of $0.8 \mathrm{~mm}$ but not exceeding $1.2 \mathrm{~mm}$ is recommended for joining the $4 \mathrm{~mm}$ thick pre-drilled Al alloy to the ABS polymer via the use of the described novel welding process. Fig.5. reveals the effect of the compressive-shearing effect of the plunging tool on the hole wall in DH and DHT joints. An increase in both the tool plunging depth $(0.8-12 \mathrm{~mm})$ and rotational speed $(710-900$ $\mathrm{rpm}$ ) increases the compressive-shearing effect on the unthreaded hole wall as revealed in Fig.5a and b. However, more deformation-induced hole wall shearing and plasticized Al fragments ensue in the hybrid Al/ABS joint (DH joint) obtained at higher plunge depth and tool rotational speed (see Fig.5b as compared to Fig.5b). This indicates that Al-ABS 
interlocking also emanates from hole wall-shearing at an increased plunge depth and rotational speed. However, the amount of the plasticized Al fragmentation (from the threaded hole) in the re-solidified ABS (see Fig.5c) is greater in the DHT joint obtained at $900 \mathrm{rpm}$ as compared to Fig.5b obtained at the same parameters. This occurrence is due to the presence of wall undulation or pitch-crest wall. It is important to examine the role of tool speed on the shoulder-induced plunge zone of the joint as it has been revealed that mechanical interlocks or Al anchors are greater in the DHT joints at higher plunge depth.
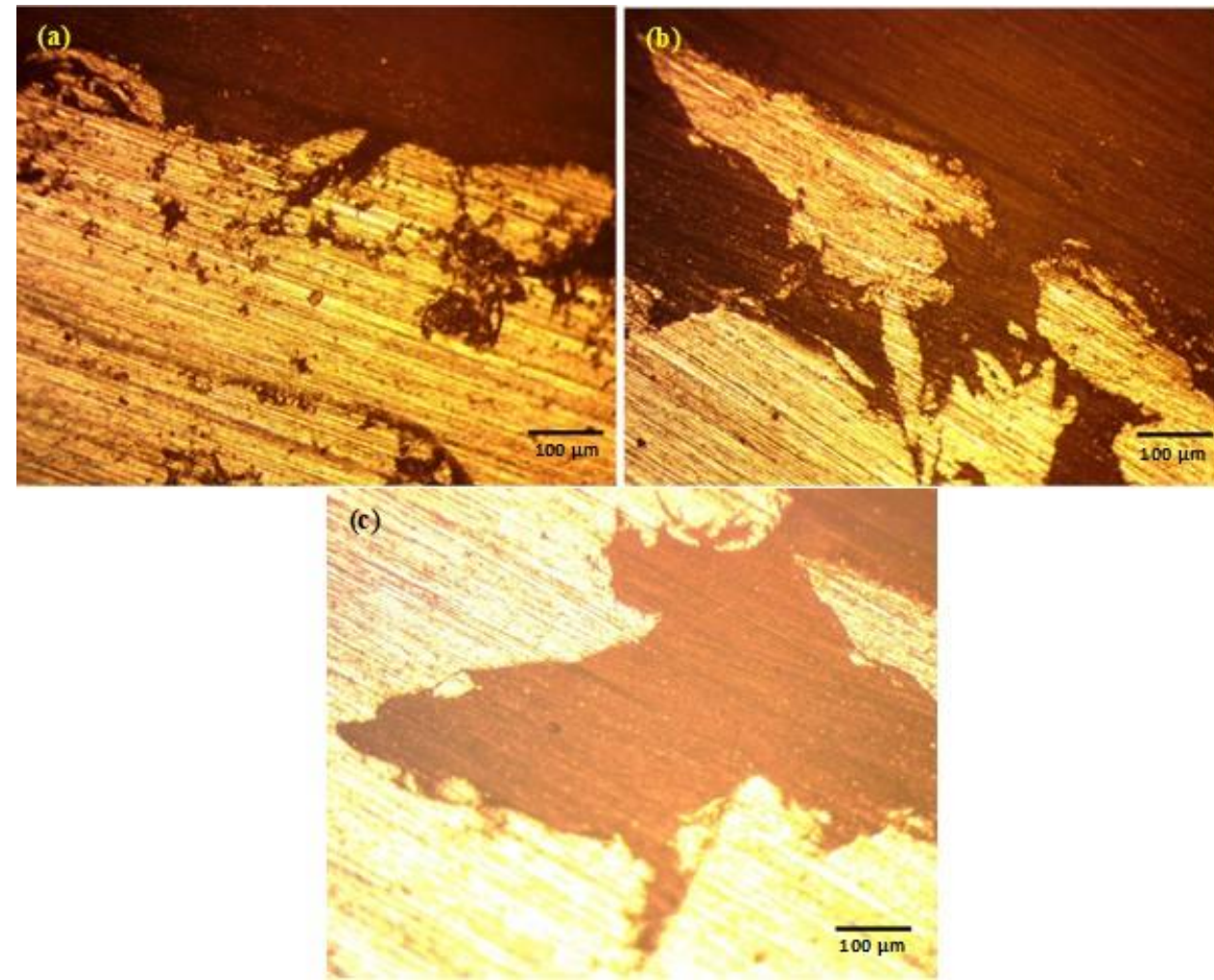

Fig. 5 Hole wall fragmentation around the tool-shoulder plunged zone (a) and (b) unthreaded hole, (c) threaded hole

Fig.6 shows the effect of tool rotational speed on the hybrid Al/ABS joints within the plasticized regions of the pre-fabricated holes (threaded and unthreaded). The combined stirring, compressive-shearing, and frictional effects on the upper Al plate cause a downward deformation-induced material flow and shearing to form $\mathrm{Al}$ particles and anchors/chips embedded with the re-solidified ABS matrix (as shown in Fig.6). The amount of the flow-induced $\mathrm{Al}$ anchors within the re-solidified ABS matrix establishes a varying degree of mechanical interlocks with the polymer depending on the level of tool rotational speed (see Fig.6a-c). The area of the sheared Al particles and anchors/chips is directly proportional to the level of the tool rotational speed as the percentage of sheared $\mathrm{Al}$ anchors/chips is revealed to increase as the tool rotational speed is increased from 900 rpm to 1120 rpm in Fig.6. Large intertwined $\mathrm{Al}$ anchors/chips are observed in the hybrid Al/ABS joint obtained at $1120 \mathrm{rpm}$ (see Fig.6c). This occurrence is attributed to the increase in thermal heat input and material flowability. The formation of tangles of trapped metallic fragments/chips in a polymer matrix was also attributed to an increase in tool rotational speed in the studies of Moghanian et al. [34]. The metal tangle/chip 
phenomenon was adjudged to have been promoted by structural disparity-aided irregular heat input distribution, a rise in thermal heat-input (at higher rotational speeds), and complex vortex-vertical-horizontal material flows. Besides, the surface area of the resolidified ABS matrix declines at the stir zone (or at the severely deformed/plasticized zone) of the joint as the tool rotational speed is increased to $1120 \mathrm{rpm}$. More sheared and dynamically recrystallized $\mathrm{Al}$ alloy is obtained at higher tool rotational speed. The large recrystallized and sheared Al alloy (at higher heat-input/rotational speed) occupies a somewhat large area being sandwiched with the melted ABS polymer at the plasticized zone (as revealed in Fig.6).

Apart from the wall difference (in the DH and DHT joints), other inherent regions of the weld have similar observations with no significant difference. Fig.7 shows the adhesive bonded and stirred $\mathrm{Al}$ regions of the hybrid $\mathrm{Al} / \mathrm{ABS}$ joint. The interfacial adhesive bonding occurs due to the wetting of the faying Al surface due to the melted ABS polymer. Upon solidification or cooling, a somewhat bonding is established in this region (see Fig.7a and b) whereas the severe plastic deformation of the $\mathrm{Al}$ side induces dynamic recrystallization in the $\mathrm{Al}$ side as revealed in Fig.7c. No porosity has been observed in the examined resolidified ABS regions of the as-welded hybrid Al/ABS joints. It should be noted that the occurrence of oxygen entrapment in the re-solidified polymer is a common feature in hybrid metal/polymer joints. The molten polymer's upward and lateral flows could also have promoted erosion of the $\mathrm{Al}$ surface to form $\mathrm{Al}-\mathrm{O}-\mathrm{C}$ interaction layers which can act as a secondary (chemical) bonding mechanism in the hybrid Al/ABS joint.

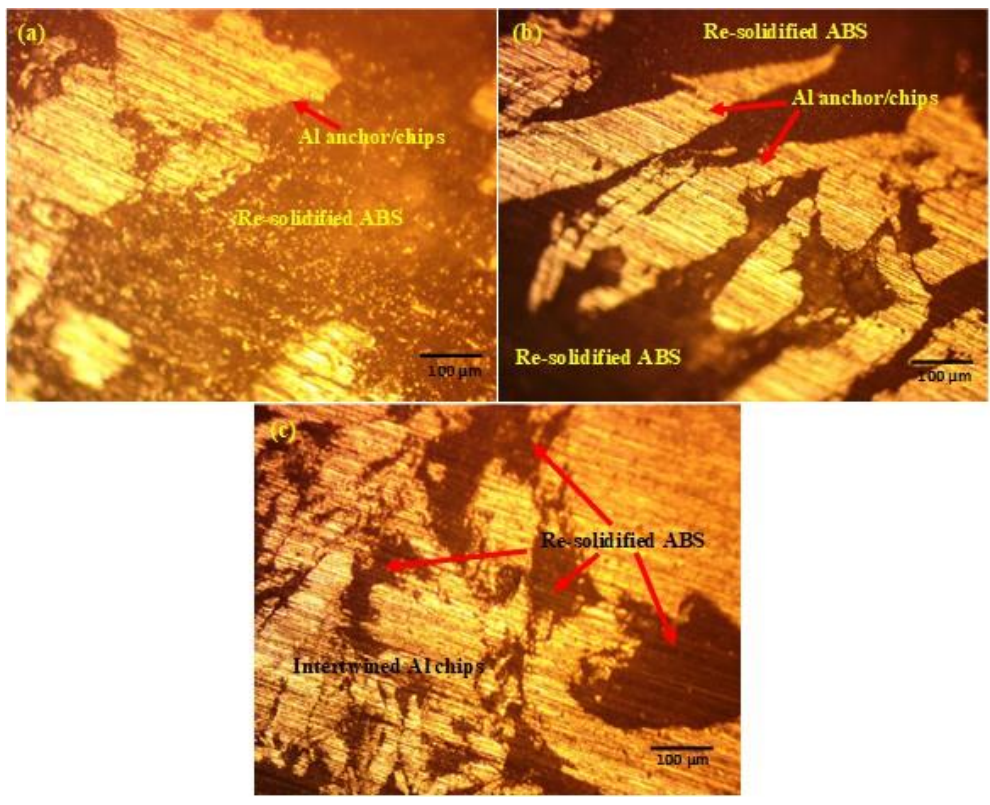

Fig. 6 Tool shoulder-induced mechanical interlocking at the weld nugget (a) $710 \mathrm{rpm}$,

(b) $900 \mathrm{rpm}$, (c) $1120 \mathrm{rpm}$ 


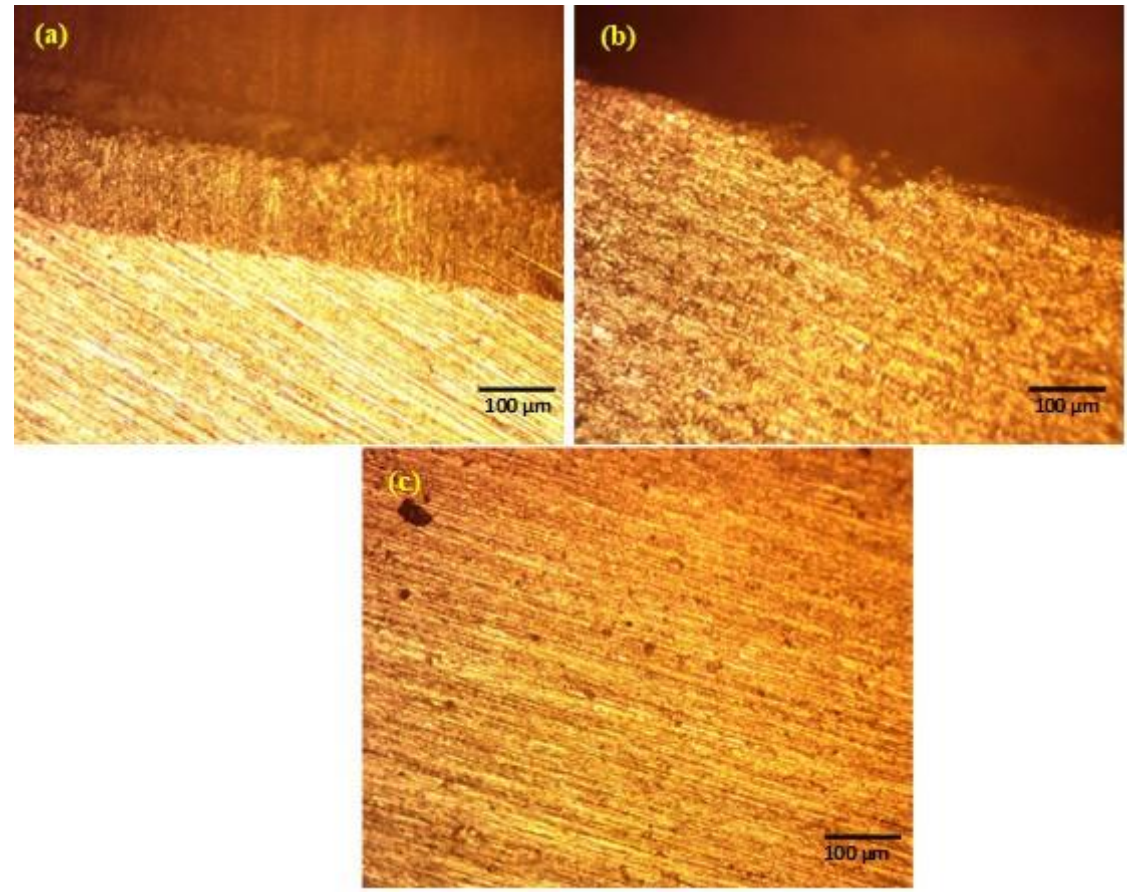

Fig. 7 Other regions of the Al/ABS joints (a) and (b) adhesion bonding, (c) stirred $\mathrm{Al}$

\subsection{Tensile Strength}

Fig. 8 shows the tensile-shear failure loads of the hybrid Al/ABS joints (DH and DHT) obtained at different levels of tool rotational speed and constant plunge depth of $1.2 \mathrm{~mm}$. An increase in the level of the tool rotational speed increases the tensile-shear failure load of the DH and DHT joints (see Fig.8). The rise in the tool rotational speed is adjudged to have increased the localized weld heat-input, polymer flowability [35], wettability of Al surface (at the faying region), and the embedded Al (anchors and threading) for mechanical interlocking in the hybrid Al/ABS joint. The increase in the tool rotational speed favors the wettability of the Al surface and this occurrence is expected to increase the adhesion area (secondary bonding mechanism) of the hybrid Al/ABS joint. The tensileshear failure loads of the DH and DHT joints consequently improved from 572-705 and 654-749 $\mathrm{N}$ respectively as the tool rotational speed is increased from 710-1120 rpm and at a constant plunge depth of $1.2 \mathrm{~mm}$ (see Fig.8). This occurrence could also be attributed to the formation of a large-area fraction of Al anchor/chips at higher tool rotational speed (revealed in Fig.6c). Paul et al. [36] described that the size of mechanical interlocking directly affects the tensile force of the metal-polymer joint. The established large $\mathrm{Al}$ anchor is considered to have improved mechanical interlocking of the $\mathrm{Al}$ in the re-solidified ABS polymer and equally enhanced fracture resistance (tensile-shear failure load) of the joint. This observation is in agreement with the works of Patel et al. [1] as the tool-induced mechanical interlocking behavior was reported as the dominant bonding mechanism in the metal-polymer joint. The presence of a big aluminum anchor in the stir zone of $\mathrm{Al} /$ polymer was also described to enhance the mechanical interlocking and shear bond strength of the joint in the works of Huang et al. [6]. The size of the Al anchor and the interfacial gap/width between the re-solidified polymer and $\mathrm{Al}$ are reduced/lesser under 
lower heat input (low rotational speed). This incidence lowers the load-bearing capability of the Al/ABS joint produced at $710 \mathrm{rpm}$.

Smaller interfacial gap (between the re-solidified $\mathrm{ABS}$ and $\mathrm{Al}$ anchor) and bigger $\mathrm{Al}$ anchor (high volumetric fraction of $\mathrm{Al}$ anchor) are also attributed to be responsible for the improved tensile-shear failure load in the hybrid Al/ABS joint fabricated at higher tool rotational speed. Paidar et al. [28] described that a rise in the tool rotational speed increased the tensile-shear load of the Al/PP-C30S joint due to an increase in the thickness of the reaction layer, a decrease in the unfilled zone, and a substantial mechanically interlocked crest-pitch region. This feature could also have played a significant role in improving the failure load of the hybrid Al/ABS joint as the tool rotational speed is increased. Tool-induced squeezing behavior, improved macro/micro-mechanical interlocking, and inherent oxide layers (for improved adhesive bonding) are reported as attributes for the high-quality heterogeneous metal-polymer joints in the studies of Meng et al. [20]. These phenomena aid multi-scale adhesive bonding and mechanical interlocking in the metal-polymer joints. On the other hand, the threaded (DHT) joint shows an improvement over the unthreaded (DH) joint in Fig.8. This occurrence is attributed to the synergy of the threading and the frictionally induced $\mathrm{Al}$ anchor/chips responsible for mechanical interlocking of the re-solidified ABS polymer in the pre-drilled hole of the hybrid Al/ABS joints.

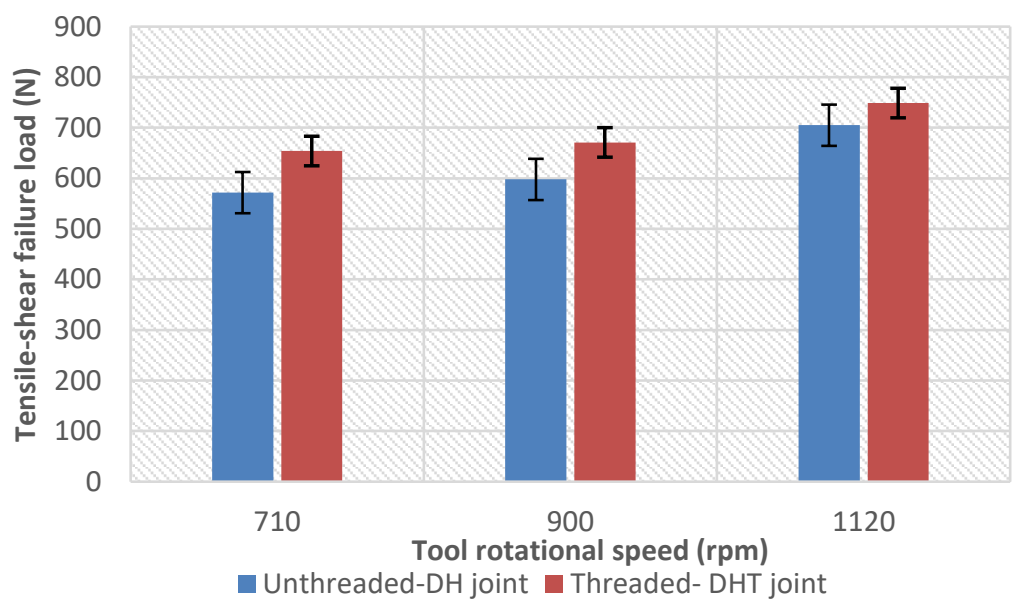

Fig. 8 Tensile-shear failure loads as a function of tool rotational speed at $1.2 \mathrm{~mm}$ plunge depth

\subsection{Fracture}

Fig.9 reveals the fracture surfaces of the hybrid Al/ABS joints (DH and DHT joints). The fracture location takes place around the base/root of the infiltrated and re-solidified (ABS) interlocked zones at lower tool speed $(710 \mathrm{rpm}$ ) in the DHT (see Fig.9a) whereas ABS pullout fracture mode ensues in the DH joint (Fig.9c). The detached threading part is observed in the bottom plate of the DHT joint (see Fig.9a). This occurrence indicates that the threading in the DHT joint inhibits the pullout of the re-solidified ABS polymer from the pre-drilled hole in Fig.9a (at $710 \mathrm{rpm}$ ) and thus improves the fracture resistance of the joint. Meanwhile, the absence of threading in the DH joint facilitates the pullout of the inherent re-solidified ABS polymer from the hole during the axial loading process (see Fig.9c). The threading-supported micro/macro interlocking around the base/root of the 
in-hole re-solidified ABS polymer is responsible for the improved tensile-shear failure load in the DHT joint as compared to the DH joint. On the other hand, the presence of mechanical $\mathrm{Al}$ anchor/interlocking at the upper tool shoulder-plunged zone significantly impacts the hybrid Al/ABS joints at high tool speed in Fig.9b and d (DH and DHT joints). The synergy of $\mathrm{Al}$ anchor and threading restrains the fracture of the hybrid Al/ABS joint (DHT joint) at higher tool rotational speed as evidence of $\mathrm{Al}$ anchor detachment is observed at the bottom plate of the joint in Fig.9b. This is due to the increase in the percentage deformationinduced $\mathrm{Al}$ anchor in the joint at $1120 \mathrm{rpm}$. Fig.9d also reveals the pullout of the resolidified ABS polymer from the pre-drilled hole. However, the presence of deformationinduced mechanical interlocking at the tool shoulder-plunged zone or the upper region of the hole (Fig.9d) offers some level of fracture resistance during the loading process (as evidence of fractured $\mathrm{Al}$ anchor is seen in the pullout part/bottom plate in Fig.9d).

The observation of the interfacial fracture surface shows that the delamination of the adhesive-bonded zone (circumferential regions around the interlocked zones) of the DHT and DH joints easily occurs during the axial loading process. This makes the interlocked zones act as the major load-bearing region, and the major stress concentration zone is considered to have acted on the interlocked zone of the hybrid Al/ABS joint. The hole threading and $\mathrm{Al}$ anchor/chips offer some degree of resistance (mechanical interlocking) to the pull-out of the re-solidified ABS from the pre-drilled hole during the tensile stressinduced nugget rotation process $[37,38]$. This phenomenon induces crack initiation and propagation at the interlocked regions of the joint. Pullout fracture is predominant in the $\mathrm{DH}$ joint with evidence of $\mathrm{Al}$ anchor-aided fracture at higher tool rotational speed while the combination of hole-threading and $\mathrm{Al}$ anchor fracture-restraining effects ensue in the DHT joint.
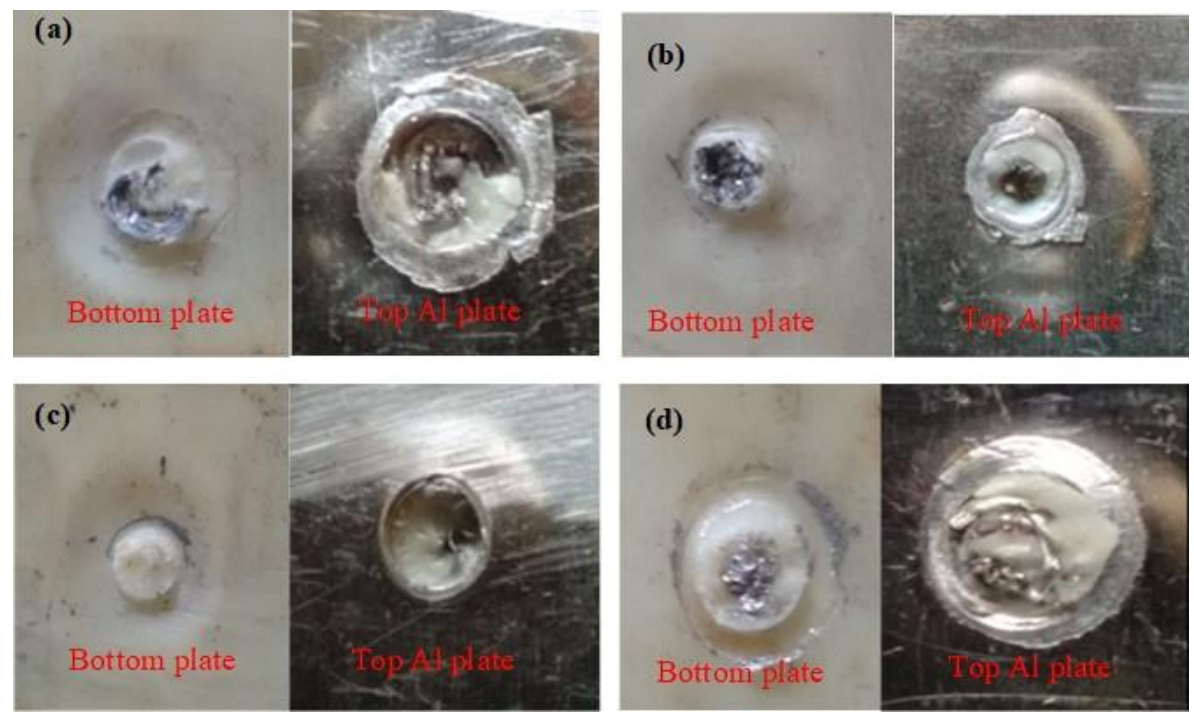

Fig. 9 Views of the fracture surfaces at the faying region of the hybrid Al/ABS joints (a) and (b) DHT joints, (c) and (d) DH joints

Delamination or debonding of the adhesive area of the joint ensues in the hybrid Al/ABS joints as has been observed in Fig.9. Thus, the fracture surfaces of the interlocked region (re-solidified ABS polymer region) are examined under SEM. Fig.10 shows the SEM images of the fracture surfaces of the hybrid Al/ABS joints (DHT and DH joints). Cohesive-adhesive (brittle) fracture is observed in the DHT joint (at low tool rotational speed) in Fig.10a as 
evidence of somewhat delaminated facets are present (see the yellow arrows) while brittle-like appearance is observed in the DH joint counterpart in Fig.10c. The fracture appearances in Fig.10a and c justify the reason for low tensile-shear failure loads in the joint fabricated at low tool rotational speeds. This observation also corroborates the works of Huang et al. [4] as the reduced polymer crystallinity, hardness, and load-bearing ability are supported by low heat input (tool rotational speed) or fast cooling rate. On the other hand, fibrous appearance (tearing of polymer) and ductile fracture mode predominate the fracture surface of the DHT joint produced at high tool rotational speed in Fig.10b. The formation of fibrils in the pulling (axial) direction is attributed to the local yielding of the polymer matrix in the works of Abibe et al. [39]. The occurrence of polymer tearing and pullout of fibers has also been reported in the works of Meng et al. [20]. This occurrence is associated with a sufficient amount of inherent mechanical interlocking in the joint. The interlocking offers resistance to polymer (ABS) pullout and it consequently results in some polymer tearing (fibrous appearance) in Fig.10b. Ductile appearance is also observed in the DH joint fabricated at high tool rotational speed in Fig.10d. It can thus be concluded that ductile fracture occurs in the hybrid Al/ABS joint obtained at high tool rotational speed and this attribute justifies the occurrence of high tensile-shear failure load in the joint. Such a high bonding strength was attributed to interfacial atomic contact, Al-O-C bonds, and nylon tearing/fragments in the studies of Liu et al. [12].
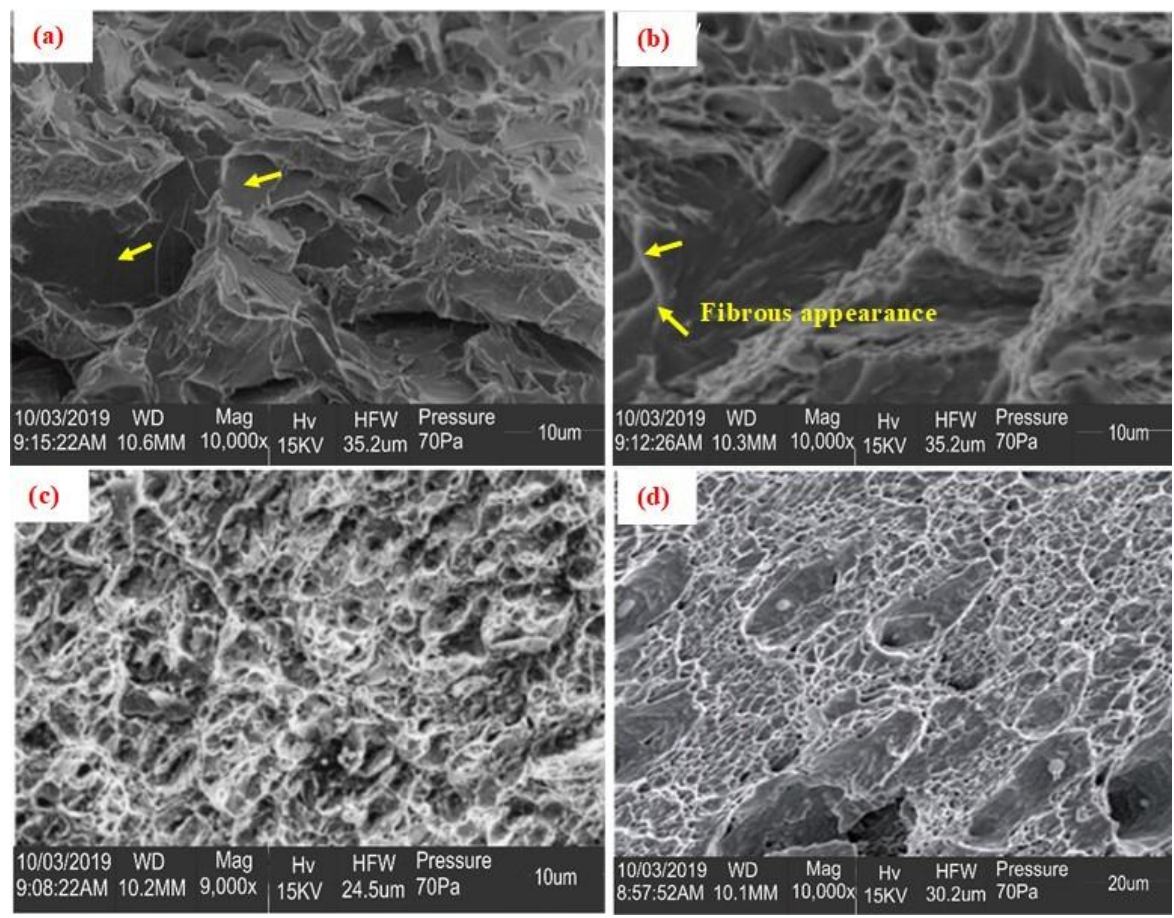

Fig. 10 SEM images of fractured re-solidified ABS matrix of the hybrid Al/ABS joints (a) and (b) DHT joints, (c) and (d) DH joints 


\section{Conclusions}

The production of hybrid $\mathrm{Al} /$ acrylonitrile butadiene styrene joints was successfully achieved via the use of pre-fabricated threaded- and unthreaded-hole friction stir spot welding approaches. The structure, tensile-shear failure load, and fracture behaviors of the irrespective joints were investigated. The findings of this investigation include:

- Tool rotational speeds of 710-1120 rpm successfully establish in-hole re-solidified ABS polymer (mechanical interlocking) in the pre-drilled unthreaded and threaded holes of the hybrid Al/ABS joint.

- The friction and deformation-induced heat input cause a decline in the local relative humidity of the hybrid Al/ABS joint during the welding process due to local heat dissipation.

- A direct interrelationship exists between the peak temperature and tool rotational speed of the hybrid Al/ABS joint. Maximum peak temperatures of 245, 276, 369oC were obtained at tool rotational speeds of 710, 900, and $1120 \mathrm{rpm}$ respectively.

- Plastic deformation/compressive shearing-induced and threading-induced mechanical interlocks, and adhesion bonding are the bonding mechanisms of the threaded hybrid Al/ABS joint while unthreaded joint is devoid of threading-aided mechanical interlock.

- A rise in the tool rotational speed increases the compressive-shearing effect and the area of embedded $\mathrm{Al}$ anchors in the re-solidified ABS polymer.

- Hybrid Al/ABS joint produced with a threaded hole has a higher tensile-shear failure load. An increase in the tool rotational speed (710-1120 rpm) improved the failure load of the unthreaded and threaded hybrid Al/ABS joints from 572-705 and 654-749 $\mathrm{N}$ respectively due to enhanced mechanical interlocking, smaller interfacial gap (between the re-solidified $\mathrm{ABS}$ and $\mathrm{Al}$ anchor), and bigger $\mathrm{Al}$ anchor/chip.

- An increase in the tool rotational speed changes the fracture location and modes. Brittle and ductile fracture modes are obtained at low and high tool rotational speeds.

\section{Acknowledgment}

The author acknowledges the assistance of Mr. D. S. Ukanah and Mr. U. F. Etoabasi during the laboratory studies of this work.

\section{References}

[1] Patel AR, Kotadiya DJ, Kapopara JM, Dalwadi CG, Patel NP, Rana HG. Investigation of Mechanical Properties for Hybrid Joint of Aluminium to Polymer using Friction Stir Welding (FSW). Materials Today: Proceedings, 2018; 5: 4242-4249. https://doi.org/10.1016/i.matpr.2017.11.688

[2] Ojo 00, Taban E, Kaluc E. Friction stir spot welding of aluminum alloys: A recent review. Materials Testing, 2015; 57: 609 - 627. https://doi.org/10.3139/120.110752

[3] Dawei Z, Qi Z, Xiaoguang F, Shengdun Z. Review on Joining Process of Carbon FiberReinforced Polymer and Metal: Methods and Joining Process. Rare Metal Materials and

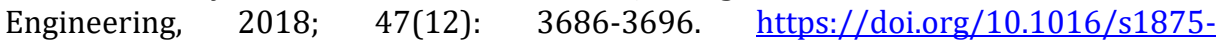
5372(19)30018-9

[4] Huang Y, Meng X, Xie Y, Wan L, Lv Z, Cao J, Feng J. Friction stir welding/processing of polymers and polymer matrix composites. Composites Part A: Applied Science and Manufacturing, 2018; 105: $235-257$. https://doi.org/10.1016/j.compositesa.2017.12.005 
[5] Kumar R, Singh R, Ahuja IPS, Penna R, Feo L. Weldability of thermoplastic materials for friction stir welding- A state of art review and future applications. Composites Part B, 2018; 137: 1-15. https://doi.org/10.1016/i.compositesb.2017.10.039

[6] Huang Y, Meng X, Wang Y, Xie Y, Zhou L. Joining of aluminum alloy and polymer via friction stir lap welding. Journal of Materials Processing Tech., 2018; 257: 148154. https://doi.org/10.1016/j.jmatprotec.2018.02.043

[7] Wang H, Yang K, Liu L. The analysis of welding and riveting hybrid bonding joint of aluminum alloy and polyether-ether-ketone composites. Journal of Manufacturing Processes, 2018; 36: 301-308. https://doi.org/10.1016/i.jmapro.2018.10.031

[8] Lambiase F, Genna S. Experimental analysis of Laser-assisted joining of Al-Mg aluminum alloy with Polyetheretherketone (PEEK). International Journal of Adhesion and Adhesives, 2018; 84: 265 - 274. https://doi.org/10.1016/j.ijadhadh.2018.04.004

[9] Dalwadi CG, Patel AR, Kapopara JM, Kotadiya DJ, Patel ND, Rana HG. Examination of Mechanical Properties for Dissimilar Friction Stir Welded Joint of Al Alloy (AA-6061) to ABS (Acrylic). Materials Today: Proceedings, 2018; 5: 4761-4765. https://doi.org/10.1016/i.matpr.2017.12.049

[10] Rout A, Pandey P, Oliveira EF, da Silva Autreto PA, Gumaste A, Singh A, Galvao DS, Arora A, Tiwary CS. Atomically locked interfaces of metal (Aluminum) and polymer (Polypropylene) using mechanical friction. Polymer, 2019; 169: 148-153. https://doi.org/10.1016/i.polymer.2019.02.049

[11] Liu FC, Dong P, Lu W, Sun K. On formation of Al-O-C bonds at aluminum/polyamide joint interface. Applied Surface Science, 2019; 466: $202-209$. https://doi.org/10.1016/j.apsusc.2018.10.024

[12] Liu FC, Dong P, Pei XA. high-speed metal-to-polymer direct joining technique and underlying bonding mechanisms. Journal of Materials Processing Tech., 2020; 280: 116610. https://doi.org/10.1016/i.jmatprotec.2020.116610

[13] Derazkola HA, Simchi A. An investigation on the dissimilar friction stir welding of Tjoints between AA5754 aluminum alloy and poly(methylmethacrylate). Thin-Walled Structures, 2019; 135: 376-384. https://doi.org/10.1016/j.tws.2018.11.027

[14] Derazkola HA, Elyasi M. The influence of process parameters in friction stir welding of Al-Mg alloy and polycarbonate. Journal of Manufacturing Processes, 2018; 35: 8898. https://doi.org/10.1016/i.jmapro.2018.07.021

[15] Xiong X, Zhao P, Ren R, Zhang Z, Cui X, Ji S. Enhanced resistance-welding hybrid joints of titanium alloy/thermoplastic composites using a carbon-nanotube lamina. Diamond \& $\quad$ Related Materials, 2020; 101: 107611. https://doi.org/10.1016/j.diamond.2019.107611

[16] Ozlati A, Movahedi M, Tamizi M, Tartifzadeh Z, Alipour S. An alternative additive manufacturing-based joining method to make Metal/ Polymer hybrid structures. Journal of Manufacturing Processes, 2019; 45: 217 226. https://doi.org/10.1016/i.jmapro.2019.07.002

[17] Hajideh MR, Farahani M, Ramezani NM. Reinforced Dissimilar Friction Stir Weld of Polypropylene to Acrylonitrile Butadiene Styrene with Copper Nanopowder. Journal of Manufacturing Processes, 2018; 32: 445-454. https://doi.org/10.1016/i.jmapro.2018.03.010

[18] Hong S-T, Das H, Oh H-S, Alam Al Nasim MNE, Chun D-M. Combination of nano-particle deposition system and friction stir spot welding for fabrication of carbon/aluminum metal matrix composite joints of dissimilar aluminum alloys. CIRP Annals Manufacturing Technology, 2017; 66: 261264. https://doi.org/10.1016/j.cirp.2017.04.115

[19] Derazkola HA, Simchi A. A new procedure for the fabrication of dissimilar joints through injection of colloidal nanoparticles during friction stir processing: Proof concept for AA6062/ABS joints. Journal of Manufacturing Processes, 2020; 49: 335 343. https://doi.org/10.1016/i.jmapro.2019.12.008 
[20] Meng X, Huang Y, Xie Y, Li J, Guan M, Wan L, Dong Z, Cao J. Friction self-riveting welding between polymer matrix composites and metals. Composites Part A: Applied Science and Manufacturing, 2019;

127: 105624. https://doi.org/10.1016/i.compositesa.2019.105624

[21] Liu Y, Zhuang W, Wu S. Damage to carbon fiber reinforced polymers (CFRP) in hole clinched joints with aluminum alloy and CFRP. Composite Structures, 2020; 234: 111710. https://doi.org/10.1016/j.compstruct.2019.111710

[22] Lambiase F, Paoletti A. Friction-assisted clinching of Aluminum and CFRP sheets. Journal of Manufacturing Processes, 2018; 31: 812-822. https://doi.org/10.1016/j.jmapro.2018.01.014

[23] Aliasghari S, Skeldon P, Zhou X, Hashimoto T. Effect of an anodizing pre-treatment on AA 5052 alloy/polypropylene joining by friction stir spot welding. Materials Science \& Engineering B, 2019; 245: 107-112. https://doi.org/10.1016/i.mseb.2019.05.018

[24] Aliasghari S, Ghorbani M, Skeldon P, Karami H, Movahedi M. Effect of plasma electrolytic oxidation on joining of AA 5052 aluminum alloy to polypropylene using friction stir spot welding. Surface \& Coatings Technology, 2017; 313: 274-281. https://doi.org/10.1016/j.surfcoat.2017.01.084

[25] Han SC, Wu LH, Jiang CY, Li N, Jia CL, Xue P, Zhang H, Zhao HB, Ni DR, Xiao BL, Ma ZY. Achieving a strong polypropylene/aluminum alloy friction spot joint via a surface laser processing pretreatment. Journal of Materials Science and amp; Technology, 2020; 50: 103-114. https://doi.org/10.1016/j.jmst.2020.02.035

[26] Goushegir SM, dos Santos JF, Amancio-Filho ST. Friction Spot Joining of aluminum AA2024/carbon-fiber-reinforced poly(phenylene sulfide) composite single-lap joints: Microstructure and mechanical performance. Materials and Design, 2014; 54: 196-206. https://doi.org/10.1016/i.matdes.2013.08.034

[27] Nagatsuka K, Yoshida S, Tsuchiya A, Nakata K. Direct joining of carbon-fiberreinforced plastic to an aluminum alloy using friction lap joining. Composites: Part B, 2015; 73: 82-88. https://doi.org/10.1016/i.compositesb.2014.12.029

[28] Paidar M, Ojo 00, Moghanian A, Pabandi HK, Elsa M. Pre-threaded hole friction stir spot welding of AA2219/PP-C30S sheets. Journal of Materials Processing Tech., 2019; 273: 116272. https://doi.org/10.1016/i.jmatprotec.2019.116272

[29] Pabandi HK, Movahedi M, Kokabi AH. A New Refill Friction Spot Welding Process for Aluminum/Polymer Composite Hybrid Structures. Composite Structures, 2017; 174: 59 - 69. https://doi.org/10.1016/i.compstruct.2017.04.053

[30] Aliasghari S, Skeldon P, Zhou X, Ghorbani M. Influence of PEO and mechanical keying on the strength of AA 5052 alloy/polypropylene friction stir spot welded joints. International Journal of Adhesion and Adhesives, 2019; 92: 65-72. https://doi.org/10.1016/j.ijadhadh.2019.04.002

[31] Oladimeji 00, Taban E, Kaluc E. Understanding the role of welding parameters and tool profile on the morphology and properties of expelled flash of spot welds. Materials \& Design, 2016; 108: 518 - 528. https://doi.org/10.1016/j.matdes.2016.07.013

[32] Ojo 00, Taban E. Hybrid multi-response optimization of friction stir spot welds: failure load, effective bonded size and flash volume as responses. Sādhanā, 2018; 43(6): 1-13. https://doi.org/10.1007/s12046-018-0882-2

[33] Ojo 00. Multi-Objective Optimization of Friction Stir Spot Welds of Aluminum Alloy Using Entropy Measurement. International Journal of Engineering Research in Africa, 2019; 45: 28 - 41. https://doi.org/10.4028/www.scientific.net/jera.45.28

[34] Moghanian A, Paidar M, Seyedafghahi SS, Ojo 00. Friction stir welding of pure magnesium and polypropylene in a lap-joint configuration: Microstructural and mechanical properties. International Journal of Minerals, Metallurgy, and Materials, 2019; 26(6): 766-774. https://doi.org/10.1007/s12613-019-1784-y 
[35] Zhao S, Kimura F, Kadoya S, Kajihara Y. Experimental analysis on mechanical interlocking of metal-polymer direct joining. Precision Engineering, 2020; 61: 120 - 125. https://doi.org/10.1016/j.precisioneng.2019.10.009

[36] Paul H, Luke M, Henning F. Combining mechanical interlocking, force fit and direct adhesion in polymer-metal-hybrid structures - Evaluation of the deformation and damage behavior. Composites Part B: Engineering, 2015; 73:158-165. https://doi.org/10.1016/j.compositesb.2014.12.013

[37] Ojo 00, Taban E, Kaluc E. Effect of residual Alclad on friction stir spot welds of AA2219 alloys. Materials Testing, 2018; 60: 979 - 988. https://doi.org/10.3139/120.111245

[38] Ojo 00, Taban E. Assessment of Effective Nugget Size, Nugget Rotation and Failure Mode of Friction Stir Spot Welds of AA2219-0 Alloy, Journal of Engineering and Engineering Technology, 2018; 12: 54-62

[39] Abibe AB, Amancio-Filho ST, dos Santos JF, Hage E. Mechanical and failure behavior of hybrid polymer-metal staked joints. Materials \& Design, 2013; 46: 338-347. https://doi.org/10.1016/j.matdes.2012.10.043 